\title{
The polymorphism and the geographical distribution of the knockdown resistance $(k d r)$ of Anopheles sinensis in the Republic of Korea
}

\author{
Seunghyun Kang ${ }^{1}$, Jongwoo Jung ${ }^{2}$, Sanghui Lee ${ }^{1}$, Heeseung Hwang ${ }^{1}$ and Won Kim*
}

\begin{abstract}
Background: In the Republic of Korea (ROK), six sibling species of the Anopheles sinensis complex are considered the vector species of malaria, but data on their susceptibilities to malaria and vector capacities have been controversial. The intensive use of insecticides has contributed to the rapid development and spread of insecticide resistance in the An. sinensis complex. Knockdown resistance (kdr) to pyrethroids and DDT in the An. sinensis complex is associated with a mutation in codon 1014 of the voltage-gated sodium channel (VGSC) gene. Because the degree of insecticide resistance varies among mosquito species and populations, the detection of kdr mutations among the six sibling species of the An. sinensis complex is a prerequisite for establishing effective long-term vector control strategies in the ROK.
\end{abstract}

Methods: In order to investigate species-specific kdr mutations, An. sinensis complex specimens have been collected from 22 sites in the ROK. Because of the difficulties with species identifications that are based only on morphological characteristics, molecular identification methods have been conducted on every specimen. Part of the IIS6 domain of the VGSC was polymerase chain reaction-amplified and directly sequenced.

Results: The molecular analyses revealed that mutations existed at codon 1014 only in An. sinensis sensu stricto and no mutations were found in the other five Anopheles species. In An. sinensis s.S., one wild type (TTG L1014) and three mutant types (TIT L1014F, TTC L1014F, and TGT L1014C) of kdr alleles were detected. The TTC L1014F mutation was observed for the first time in this species.

Conclusions: The fact that the highly polymorphic kdr gene is only observed in An. sinensis s.S., out of the six Anopheles species and their geographical distribution suggest the need for future studies of insecticide resistance monitoring and investigations of species-specific resistance mechanisms in order to build successful malaria vector control programmes in the ROK.

Keywords: Anopheles sinensis, Pyrethroid, Knockdown resistance, Kdr genotype

\section{Background}

Before the 1960s, the Republic of Korea (ROK) was a Plasmodium vivax malaria-endemic country, and malaria prevailed throughout the country. In the late 1970s, malaria was eliminated through eradication efforts by the World Health Organization and the government of the ROK. However, since 1993, malaria has re-emerged in the north-western region of Gyeonggi-do [1], and over 1,000 cases of malaria have been diagnosed every year

\footnotetext{
* Correspondence: wonkim@plaza.snu.ac.kr

'School of Biological Sciences, Seoul National University, 599 Gwanak-ro, Seoul, Republic of Korea

Full list of author information is available at the end of the article
}

with a peak of 4,142 cases diagnosed in 2000 [2]. Although the malaria-vector mosquitoes, the Anopheles species, are prevalent throughout the Korean Peninsula, most of the incident cases in the ROK have been reported in the northern part of Gyeonggi-do and the north-western part of Gangwon-do near the Demilitarized Zone (DMZ) between North Korea and the ROK [3]. An area of high transmission is found in North Korea along the DMZ as well, which suggests a parallel outbreak occurred in both countries [4].

In the ROK, eight Anopheles species, including the two recently reported species of Anopheles belenrae and 
Anopheles kleini, have been recorded so far [5,6]. These eight species belong to three groups (Hyrcanus, Barbirostris, and Lindesayi) in the subgenus Anopheles. The Hyrcanus Group consists of 27 species, six in the Lesteri subgroup, four in the Nigerrimus subgroup, and the rest 17 unplaced species within the group [7]. The following six of these species have been reported in the ROK: Anopheles sinensis sensu stricto, Anopheles lesteri, Anopheles pullus, Anopheles sineroides, An. kleini and An. belenrae $[5,6,8,9]$. These six species comprise a species complex called An. sinensis sensu lato. Because they occur in sympatry and it is hard to distinguish by morphology An. belenrae and An. kleini from An. pullus and An. sinensis s.s. [10-14]. Thus, molecular methods have been used for species identification $[9,13,15,16]$. The other two non-Hyrcanus species, Anopheles koreicus and Anopheles lindesayi, belong to the Barbirostris and Lindesayi Groups, respectively [6].

The primary vector species for malaria in Korea has long been declared An. sinensis s.s. [3,13], but their $P$. vivax malaria susceptibilities and vectorial capacities have been controversial. Recent studies have suggested that An. pullus, An. kleini and An. lesteri are the primary vector species and that An. sinensis s.s. does not play a primary role $[2,15,17]$. In addition, An. sineroides and $A n$. belenrae have been reported as $P$. vivax-positive based on enzyme-linked immunosorbent assays and polymerase chain reactions (PCR) $[18,19]$.

Because all six species of $A n$. sinensis s.l. in the ROK transmit the malaria parasite $P$. vivax, studying their discriminative ecology, such as their blood feeding and resting behaviours, their larval habitats, and their responses to insecticides, is necessary for malaria control. Hybridization between related species of the anopheline species, which rarely takes place in natural environments, might complicate malaria vector control [20-23]. Evidence of introgressive hybridization has been reported for the Anopheles gambiae complex [20-26]. In addition, recent studies have reported the presence of natural hybrids between some anopheline species in the ROK [27].

Until now, the use of insecticides has been the most effective and economical vector control method for malaria and other vector-borne diseases, such as dengue and filariasis [28]. Since the first introduction of insecticides to the ROK in the 1970s, pyrethroids and organophosphates have been used throughout the country in order to control medically and agriculturally important arthropod pests, including mosquitoes. The national malaria eradication programme that was based mostly on the chemical control of vector mosquitoes was successful in the 1990s in the ROK. However, overdoses of insecticide have quickly led to the presence and spread of insecticide-resistant mosquitoes [13], which have caused serious problems for malaria-controlling interventions.
Resistance to pyrethroids and DDT, which is known as knockdown resistance $(k d r)$, is caused by a single mutation in the S6 transmembrane segment of domain II in the voltage-gated sodium channel (VGSC) gene [29]. Several mutations at codon 1014, such as L1014F (Leu-to-Phe), L1014S (Leu-to-Ser), and L1014C (Leuto-Cys) have been reported in many Anopheles species, including An. gambiae, Anopheles arabiensis, Anopheles culicifacies, Anopheles stephensi, An. sinensis complex, Anopheles sacharovi, Anopheles subpictus, Anopheles sundaicus, Anopheles aconitus, and Anopheles vagus [30-37]. A positive correlation between the $k d r$ genotype and the resistance phenotype to pyrethroids and DDT in the Anopheles species was well documented by articles $[34,38,39]$.

A previous study reported that the frequencies of the $k d r$ allele of An. sinensis in the ROK ranged from 25.0 to $96.6 \%$, which suggested that pyrethroid resistance was already widespread in natural populations of the ROK [34]. A standard World Health Organization insecticide susceptibility test was conducted on the Anopheles species in the ROK [40-42], and the results showed the development and widespread distribution of pyrethroidresistant phenotypes. In order to monitor knockdown mutations of pyrethroid resistance in An. sinensis, realtime PCR amplification of a specific allele (rtPASA) has been developed. The results suggested that L1014F mutation was a major allele that showed a high allele frequency, whereas L1014C mutation was a minor allele that showed a low allele frequency within the An. sinensis populations in the ROK [34]. However, these previous studies conducted chemical and molecular assays on the An. sinensis group and species-specific assays have never been conducted because the sibling species are morphologically indistinguishable, and, unlike An. sinensis s.s., the other species have relatively low population densities. Because the mechanisms and degree of insecticide resistance vary among species and populations [43-46], the present study aimed to explore the species-specific distribution of $k d r$ resistance alleles in all members of the An. sinensis complex in the ROK.

\section{Methods}

\section{Mosquito collections and species identification}

Mosquitoes were collected from 22 locations (Figure 1, Table 1) in the ROK with a CDC Miniature Light Trap (John W Hock Company, Gainesville, FL, USA) and preserved on site using dry ice. Because it is morphologically hard to distinguish the species within the An. sinensis complex, the mosquito specimens were isolated based on their morphological characteristics that were determined first under a stereomicroscope in the laboratory compared to the other insects, and then the specific species of all of the Anopheles specimens were identified using 


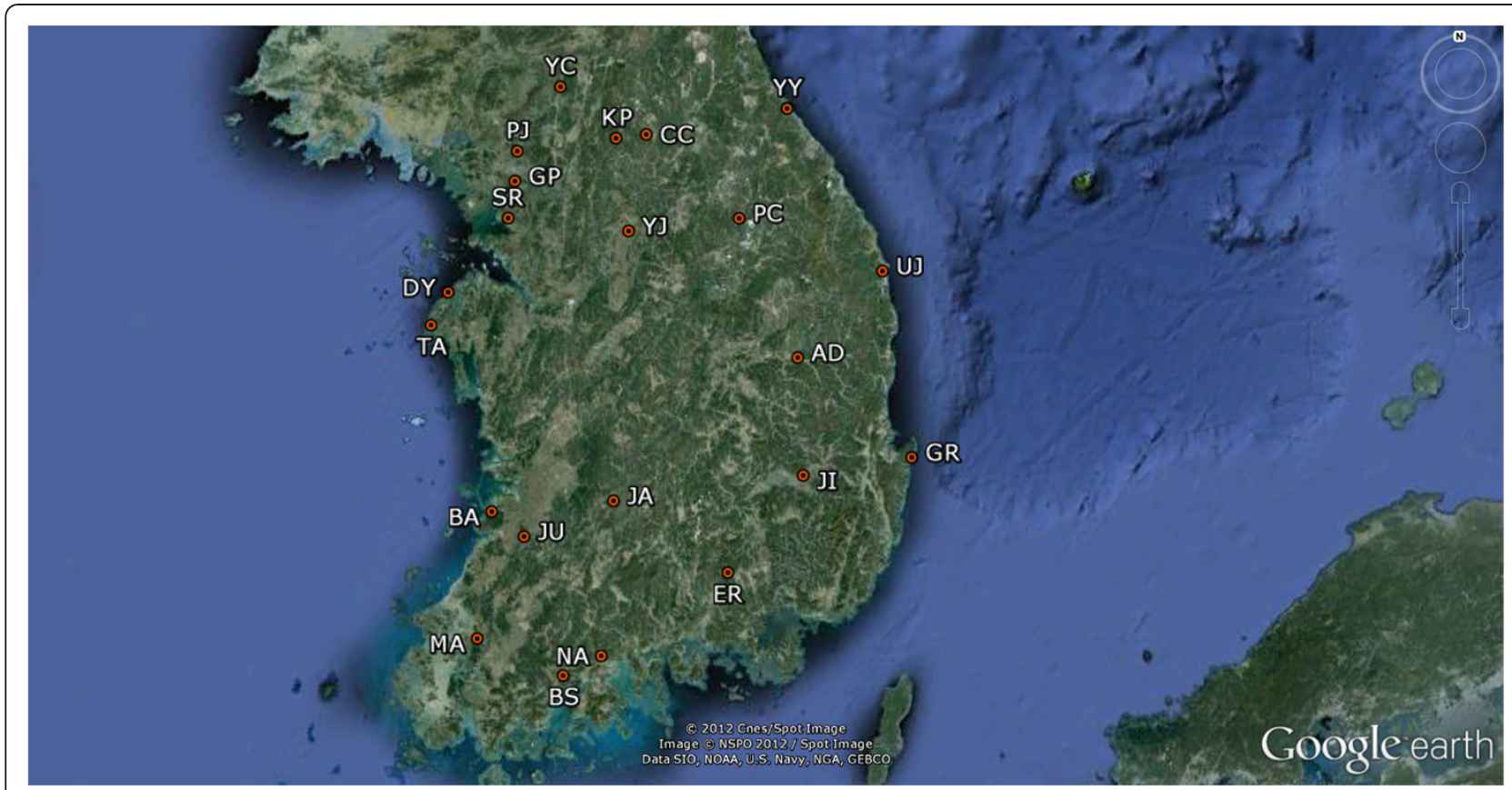

Figure 1 The geographical locations of the sampling sites in a map of the Republic of Korea (ROK).

multiplex assays [47]. DNA was extracted from the entire body or legs by following a standard phenol extraction protocol or DNeasy Blood and Tissue kit (QIAGEN, USA).

\section{DNA sequencing of VGSC}

In order to detect the $k d r$ mutation, part of the IIS6 domain of the VGSC was PCR amplified and directly sequenced using 5'ASIIS56 and 3'ASIIS56 intron primers [34]. The sequences were determined using an $\mathrm{ABI}$ 3730xl DNA analyser (Applied Biosystems, USA) and visually confirmed using Sequence Navigator 1.1 software (Applied Biosystems, USA). The obtained sequences were aligned with Clustal X version 2.0 [48]. The deduced amino acid comparisons were conducted by MEGA version 5 [49].

\section{Statistical analyses}

The maximum likely frequency (y) of an allele present or absent in a sample of a given size $(\mathrm{x})$ was obtained from the upper of $95 \%$ confidence limit of binomial distribution, given by $\mathrm{y}=1-0.05^{1 / \mathrm{x}}$, following the example of Post and Millest [50].

\section{Results}

\section{Species composition and distribution}

A total of 755 An. sinensis complex mosquitoes were collected from 22 sites in the ROK, as briefly described in Figure 1 and Table 1. As a result of the molecular identifications that were conducted by multiplex assays (Table 1), most of the specimens were An. sinensis s.s. (665 of 755, 88.08\%), which is known as the dominant species in the ROK, and these were followed by $A n$. kleini (30 of 755, 3.97\%), An. pullus (26 of 755, 3.44\%), An. sineroides (19 of 755, 2.52\%), An. lesteri (13 of 755, $1.72 \%$ ), and An. belenrae (two of 755, 0.26\%). Hybrid individuals were not detected. An. sinensis s.s. was found at most of the sites (21 of 22), whereas the other species were found at a few sites (one to five of 22) in the northern part of the ROK, and these results were in concordance with previous studies showing topoclinal distributions.

\section{kdr mutations}

In order to examine the mutations at codon 1014, 343bp sequences of part of the IIS6 domain of the VGSC gene were obtained from a total of 177 specimens that consisted of An. sinensis s.s. $(\mathrm{n}=87)$, An. kleini $(\mathrm{n}=30)$, An. pullus $(\mathrm{n}=26)$, An. belenrae $(\mathrm{n}=2)$, An. lesteri $(\mathrm{n}=13)$, and An. sineroides $(\mathrm{n}=19)$ from 10 sites in the ROK (Table 2 and 3). The DNA sequences were different among the species. However, the deduced amino acid sequences showed no non-synonymous mutations within the VGSC-coding regions in all six species, except for at codon 1014. Pyrethroid- and DDT-resistant $k d r$ mutations were detected in An. sinensis s.s. only, and the other five species had the wild-type $k d r$ allele L1014 only (Figure 2, Table 2 and 3). Interestingly, An. sineroides 
Table 1 Summary of regional information and the species composition of the An. sinensis complex

\begin{tabular}{|c|c|c|c|c|c|c|c|c|}
\hline \multirow[t]{2}{*}{ Name } & \multirow[t]{2}{*}{ Sample Sites } & \multirow[t]{2}{*}{$\mathrm{N}$} & \multicolumn{6}{|c|}{ Identified Species } \\
\hline & & & An. sinensis & An. pullus & An. kleini & An. belenrae & An. lesteri & An. sineroeides \\
\hline$A D$ & ANDONG & 16 & 16 & 0 & 0 & 0 & 0 & 0 \\
\hline BA & BUAN & 16 & 16 & 0 & 0 & 0 & 0 & 0 \\
\hline BS & BOSEONG & 13 & 13 & 0 & 0 & 0 & 0 & 0 \\
\hline CC & CHOONCHEON & 8 & 8 & 0 & 0 & 0 & 0 & 0 \\
\hline DY & DANYANG & 15 & 15 & 0 & 0 & 0 & 0 & 0 \\
\hline ER & EUIRYEONG & 25 & 25 & 0 & 0 & 0 & 0 & 0 \\
\hline GP & GIMPO & 237 & 208 & 10 & 5 & 2 & 12 & 0 \\
\hline GR & GURYONGPO & 17 & 17 & 0 & 0 & 0 & 0 & 0 \\
\hline$J A$ & JINAN & 11 & 11 & 0 & 0 & 0 & 0 & 0 \\
\hline ال & JAIN & 29 & 29 & 0 & 0 & 0 & 0 & 0 \\
\hline JU & JEONGEUP & 10 & 10 & 0 & 0 & 0 & 0 & 0 \\
\hline KP & KAPYEONG & 14 & 14 & 0 & 0 & 0 & 0 & 0 \\
\hline MA & MOOAN & 6 & 6 & 0 & 0 & 0 & 0 & 0 \\
\hline NA & NAKAN & 28 & 28 & 0 & 0 & 0 & 0 & 0 \\
\hline$P C$ & PYEONGCHANG & 8 & 0 & 0 & 8 & 0 & 0 & 0 \\
\hline PJ & PAJOO & 127 & 114 & 13 & 0 & 0 & 0 & 0 \\
\hline$S R$ & SORAE & 25 & 24 & 0 & 0 & 0 & 1 & 0 \\
\hline TA & TAEAN & 12 & 12 & 0 & 0 & 0 & 0 & 0 \\
\hline UJ & ULJIN & 16 & 16 & 0 & 0 & 0 & 0 & 0 \\
\hline YC & YEONCHEON & 80 & 62 & 3 & 15 & 0 & 0 & 0 \\
\hline YJ & YEOJOO & 12 & 11 & 0 & 1 & 0 & 0 & 0 \\
\hline \multirow[t]{2}{*}{ YY } & YANGYANG & 30 & 10 & 0 & $n$ & 0 & 0 & 19 \\
\hline & & 755 & 665 & 26 & 30 & 2 & 13 & 19 \\
\hline
\end{tabular}

had a different amino-acid coding sequence (TTA). But the same amino acid (leucine) occurred at codon 1014. Met-Thr mutation at codon 918 (M918T), or super- $k d r$, which enhances the resistance in combination with L1014F within the same genetic region was not detected in any of the six species.

\section{An. sinensis s.s.}

A total of four types, which consisted of one wild type (TTG L1014) and three mutant types (TTT L1014F, TTC L1014F, and TGT L1014C), of $k d r$ alleles were detected in An. sinensis s.s.. TTC L1014F was found for the first time. TTT L1014F was the dominant mutation in all of the regions, whereas TTC L1014F, which was distributed in the eastern part of the ROK alongside the Taebaek Mountain (YY, AD, and GR in Figure 1 and Table 1 and 2), existed only in the heterozygotic state (Table 2). The allele frequencies of L1014 ranged from $7.7 \%$ to $75.0 \%$, while that of L1014F (TTT) ranged from $0 \%$ to $70.6 \%$, that of $\mathrm{L} 1014 \mathrm{~F}$ (TTC) ranged from $0 \%$ to $14.7 \%$, and that of L1014C ranged from $0 \%$ to $23.1 \%$ (Table 3).

\section{Discussion}

Knockdown resistance $(k d r)$ is caused by mutations at codon 1014 of the VGSC, which is the target of pyrethroids and DDT. In this study, molecular analysis of the VGSC in the An. sinensis complex in the ROK revealed that mutations at codon 1014 existed only in An. sinensis s.s., whereas no $k d r$ mutations were observed in the other five species, including An. pullus, An. kleini, An. sineroides, An. lesteri and An. belenrae. For wild-type L1014, a previous comparative study of the VGSC of various taxa showed different usages of coding triplets at L1014 [51], while in the present results, the amino-acid coding sequences at L1014 differed between the species. The codon of L1014 was TTC in five species (An. sinensis s.s., An. pullus, An. kleini, An. lesteri and An. belenrae), whereas for An. sineroides it was TTA, which is observed in a number of species, including An. gambiae, An. arabiensis and An. vagus [30,36,37].

Pyrethroids have been widely used in large quantities for the control of agricultural pests and medically important arthropod pests through thermal fogging, residual spraying, impregnated clothing, and mosquito nets since their introduction to the ROK in the 1970s. 
Table 2 Species-specific genotype frequencies of the $k d r$ allele in each study site

\begin{tabular}{|c|c|c|c|c|c|c|c|c|c|c|c|c|}
\hline \multirow[t]{2}{*}{ Study Sites } & \multirow[t]{2}{*}{ Species } & \multirow[t]{2}{*}{$\mathbf{N}$} & \multicolumn{10}{|c|}{ Genotype Frequency (\%) } \\
\hline & & & $\mathrm{L} / \mathrm{L}$ & $L^{*} / L^{*}$ & $\mathrm{~L} / \mathrm{P}$ & $\mathrm{L} / \mathrm{C}$ & $\mathrm{P} / \mathrm{P}$ & $\mathrm{P} / \mathrm{C}$ & $\mathrm{C} / \mathrm{C}$ & $\mathrm{L} / \mathrm{P}^{*}$ & $\mathrm{P} / \mathrm{P}^{*}$ & $\mathrm{C} / \mathrm{P}^{*}$ \\
\hline \multirow[t]{3}{*}{ YC } & An. sinensis & 14 & 14.3 & 0.0 & 14.3 & 7.1 & 28.6 & 35.7 & 0.0 & 0.0 & 0.0 & 0.0 \\
\hline & An. kleini & 15 & 100.0 & 0.0 & 0.0 & 0.0 & 0.0 & 0.0 & 0.0 & 0.0 & 0.0 & 0.0 \\
\hline & An. pullus & 3 & 100.0 & 0.0 & 0.0 & 0.0 & 0.0 & 0.0 & 0.0 & 0.0 & 0.0 & 0.0 \\
\hline \multirow[t]{2}{*}{ PJ } & An. sinensis & 17 & 11.8 & 0.0 & 17.6 & 0.0 & 41.2 & 23.5 & 5.9 & 0.0 & 0.0 & 0.0 \\
\hline & An. pullus & 13 & 100.0 & 0.0 & 0.0 & 0.0 & 0.0 & 0.0 & 0.0 & 0.0 & 0.0 & 0.0 \\
\hline \multirow[t]{4}{*}{ GP } & An. kleini & 5 & 100.0 & 0.0 & 0.0 & 0.0 & 0.0 & 0.0 & 0.0 & 0.0 & 0.0 & 0.0 \\
\hline & An. lesteri & 12 & 100.0 & 0.0 & 0.0 & 0.0 & 0.0 & 0.0 & 0.0 & 0.0 & 0.0 & 0.0 \\
\hline & An. belenrae & 2 & 100.0 & 0.0 & 0.0 & 0.0 & 0.0 & 0.0 & 0.0 & 0.0 & 0.0 & 0.0 \\
\hline & An. pullus & 10 & 100.0 & 0.0 & 0.0 & 0.0 & 0.0 & 0.0 & 0.0 & 0.0 & 0.0 & 0.0 \\
\hline PC & An. kleini & 8 & 100.0 & 0.0 & 0.0 & 0.0 & 0.0 & 0.0 & 0.0 & 0.0 & 0.0 & 0.0 \\
\hline YJ & An. kleini & 1 & 100.0 & 0.0 & 0.0 & 0.0 & 0.0 & 0.0 & 0.0 & 0.0 & 0.0 & 0.0 \\
\hline BS & An. sinensis & 13 & 0.0 & 0.0 & 15.4 & 0.0 & 46.2 & 30.8 & 7.7 & 0.0 & 0.0 & 0.0 \\
\hline SR & An. lesteri & 1 & 100.0 & 0.0 & 0.0 & 0.0 & 0.0 & 0.0 & 0.0 & 0.0 & 0.0 & 0.0 \\
\hline$A D$ & An. sinensis & 16 & 50.0 & 0.0 & 0.0 & 31.3 & 0.0 & 0.0 & 0.0 & 18.8 & 0.0 & 0.0 \\
\hline GR & An. sinensis & 17 & 58.9 & 0.0 & 11.8 & 0.0 & 0.0 & 0.0 & 0.0 & 0.0 & 23.5 & 5.9 \\
\hline \multirow[t]{4}{*}{ YY } & An. sinensis & 10 & 0.0 & 0.0 & 30.0 & 0.0 & 60.0 & 0.0 & 0.0 & 10.0 & 0.0 & 0.0 \\
\hline & An. kleini & 1 & 100.0 & 0.0 & 0.0 & 0.0 & 0.0 & 0.0 & 0.0 & 0.0 & 0.0 & 0.0 \\
\hline & An. sineroides & 19 & 0.0 & 100.0 & 0.0 & 0.0 & 0.0 & 0.0 & 0.0 & 0.0 & 0.0 & 0.0 \\
\hline & & 177 & & & & & & & & & & \\
\hline
\end{tabular}

L indicates the susceptible allele L1014 (TTG), and $\mathrm{L}^{*}$ indicates the other susceptible allele L1014 (TTA). P indicates the resistance allele L1014F (TTT), and P* indicates the other codon type allele L1014F (TTC). C indicates the resistance allele L1014C (TGT).

Inevitably, a variety of mosquitoes, including malaria vectors, might have developed resistance to pyrethroids and jeopardized the successful malaria control programmes in the ROK $[34,40,42]$. A number of recent studies have reviewed the numerous cases that were examined and whether there were correlations between mutations in the VGSC and the resistance phenotype in diverse taxa $[38,51,52]$. Almost all of the results of the previous studies have shown a strong causal relationship between the $k d r$ genotype and insecticide susceptibility to pyrethroids and DDT. However, the absence of a $k d r$ mutation is not a causal factor of total susceptibility to the insecticides.

Although the detailed research on fitness costs of $k d r$ mutations, additional biochemical assays and specific gene expression studies are needed for future study, the highly polymorphic $k d r$ gene that was observed only in An. sinensis s.s. and the absence of a $k d r$ mutation in the other five species suggest two tentative hypotheses. First, because the anopheline species other than $A n$. sinensis s.s. are geographically distributed in the northern part of the ROK near the DMZ, the absence of $k d r$ mutations in these species may have resulted from migration of these $k d r$-free mosquitoes from North Korea or the DMZ to the ROK to seek for blood sources, such as cows or pigs. Along the DMZ and in North Korea, the environment was unsuitable for the mosquitoes due to the lack of blood sources. However, the amount of insecticide used in North Korea and along the DMZ was much less than the amount used in the ROK, which reduces the insecticide selection pressure [53]. This hypothesis is in concordance with the renowned hypothesis that the re-emergence of $P$. vivax in the ROK arose from North Korea through sporozoite-infected mosquitoes that dispersed from North Korea to the ROK across the DMZ [3,53-57]. Second, the highly polymorphic $k d r$ gene in An. sinensis s.s. (the dominant Anopheles mosquito in East Asia) in the ROK may be explained by their large population size and wide species range. The level of genetic variation within a species is generated by mutation and eliminated by genetic drift due to finite population size [58]. Large population size and wide species range are precondition to polymorphism, as a large effective population size will have an increased genetic variability $[59,60]$ and a higher rate of mutation [61].

For An. sinensis s.s., the geographical distribution of $k d r$ alleles is supported by a previous study that examined the population genetic structure of An. sinensis using mitochondrial control regions, and the results suggested distinct subdivisions in the Northern Group (NG) and Southern Group (SG) in the ROK [62]. The Great 
Table 3 Species-specific allele frequencies of the $k d r$ allele (and $95 \%$ confidence intervals, Cls) in each study site

\begin{tabular}{|c|c|c|c|c|c|c|c|c|c|c|}
\hline \multirow{4}{*}{ Study Sites } & \multirow{4}{*}{ Species } & \multirow{4}{*}{$\mathbf{N}$} & \multicolumn{8}{|c|}{ kdr Allele Frequency (\%) } \\
\hline & & & \multirow{2}{*}{\multicolumn{2}{|c|}{$\begin{array}{c}\text { Susceptible } \\
\text { Leu }\end{array}$}} & \multicolumn{6}{|c|}{ Resistant } \\
\hline & & & & & \multicolumn{4}{|c|}{ Phe } & \multicolumn{2}{|c|}{ Cys } \\
\hline & & & TTG & {$[95 \% \mathrm{Cl}]$} & TTT & {$[95 \% \mathrm{Cl}]$} & TTC & {$[95 \% \mathrm{Cl}]$} & TGT & {$[95 \% \mathrm{Cl}]$} \\
\hline \multirow[t]{3}{*}{ YC } & An. sinensis & 14 & 25.0 & {$[20.2-29.8]$} & 54.0 & {$[43.6-64.4]$} & 0.0 & {$[0.0-0.0]$} & 21.0 & {$[17.0-25.0]$} \\
\hline & An. kleini & 15 & 100.0 & {$[81.9-100.0]$} & 0.0 & {$[0.0-0.0]$} & 0.0 & {$[0.0-0.0]$} & 0.0 & {$[0.0-0.0]$} \\
\hline & An. pullus & 3 & 100.0 & {$[36.8-100.0]$} & 0.0 & {$[0.0-0.0]$} & 0.0 & {$[0.0-0.0]$} & 0.0 & {$[0.0-0.0]$} \\
\hline \multirow[t]{2}{*}{ PJ } & An. sinensis & 17 & 20.6 & [17.3-23.9] & 61.8 & {$[51.8-71.7]$} & 0.0 & {$[0.0-0.0]$} & 17.6 & [14.8-20.5] \\
\hline & An. pullus & 13 & 100.0 & {$[79.4-100.0]$} & 0.0 & {$[0.0-0.0]$} & 0.0 & {$[0.0-0.0]$} & 0.0 & {$[0.0-0.0]$} \\
\hline \multirow[t]{4}{*}{ GP } & An. kleini & 5 & 100.0 & {$[54.9-100.0]$} & 0.0 & {$[0.0-0.0]$} & 0.0 & {$[0.0-0.0]$} & 0.0 & {$[0.0-0.0]$} \\
\hline & An. lesteri & 12 & 100.0 & [77.9-100.0] & 0.0 & {$[0.0-0.0]$} & 0.0 & {$[0.0-0.0]$} & 0.0 & {$[0.0-0.0]$} \\
\hline & An. belenrae & 2 & 100.0 & [22.4-100.0] & 0.0 & {$[0.0-0.0]$} & 0.0 & {$[0.0-0.0]$} & 0.0 & {$[0.0-0.0]$} \\
\hline & An. pullus & 10 & 100.0 & [74.1-100.0] & 0.0 & {$[0.0-0.0]$} & 0.0 & {$[0.0-0.0]$} & 0.0 & {$[0.0-0.0]$} \\
\hline PC & An. kleini & 8 & 100.0 & [68.8-100.0] & 0.0 & {$[0.0-0.0]$} & 0.0 & {$[0.0-0.0]$} & 0.0 & {$[0.0-0.0]$} \\
\hline YJ & An. kleini & 1 & 100.0 & [5.0-100.0] & 0.0 & {$[0.0-0.0]$} & 0.0 & {$[0.0-0.0]$} & 0.0 & {$[0.0-0.0]$} \\
\hline BS & An. sinensis & 13 & 7.7 & [6.1-9.3] & 69.2 & [55.0-83.5] & 0.0 & {$[0.0-0.0]$} & 23.1 & [18.3-27.8] \\
\hline SR & An. lesteri & 1 & 100.0 & [5.0-100.0] & 0.0 & {$[0.0-0.0]$} & 0.0 & {$[0.0-0.0]$} & 0.0 & {$[0.0-0.0]$} \\
\hline$A D$ & An. sinensis & 16 & 75.0 & {$[62.2-87.8]$} & 0.0 & {$[0.0-0.0]$} & 9.0 & {$[7.5-10.5]$} & 16.0 & [13.3-18.7] \\
\hline GR & An. sinensis & 17 & 64.7 & [54.3-75.2] & 17.6 & [14.8-20.5] & 14.7 & [12.3-17.1] & 2.9 & {$[2.5-3.4]$} \\
\hline \multirow[t]{4}{*}{ YY } & An. sinensis & 10 & 23.5 & [17.4-29.6] & 70.6 & [52.3-88.9] & 5.9 & {$[4.4-7.4]$} & 0.0 & {$[0.0-0.0]$} \\
\hline & An. kleini & 1 & 100.0 & [5.0-100.0] & 0.0 & {$[0.0-0.0]$} & 0.0 & {$[0.0-0.0]$} & 0.0 & {$[0.0-0.0]$} \\
\hline & An. sineroides & 19 & $100.0^{*}$ & [85.4-100.0] & 0.0 & {$[0.0-0.0]$} & 0.0 & {$[0.0-0.0]$} & 0.0 & {$[0.0-0.0]$} \\
\hline & & 177 & & & & & & & & \\
\hline
\end{tabular}

The asterisk indicates TTA L1014 allele frequency.

Mountains, such as the Sobaek and Taebaek Mountains that cross the ROK from the northeast to southwest may play a major role as potent genetic barriers. These two groups have different genetic properties, such that the SG is genetically more diverse and has a larger number of private alleles and effective population size than the NG. A total of four $k d r$ alleles including one wild type and three mutant types were observed in this study. The three types of alleles (TTG L1014, TTT L1014F, and TGT L1014C) were observed in both the NG and the SG. Whereas the TTC L1014F allele, which was the rarest allele and which was detected for the first time in An. sinensis s.s. in this study, was only detected in the SG (AD, GR, and YY in Figure 1 and Table 2 and 3).

In summary, the different allele statuses of $k d r$ genes in the An. sinensis complex suggest the importance of

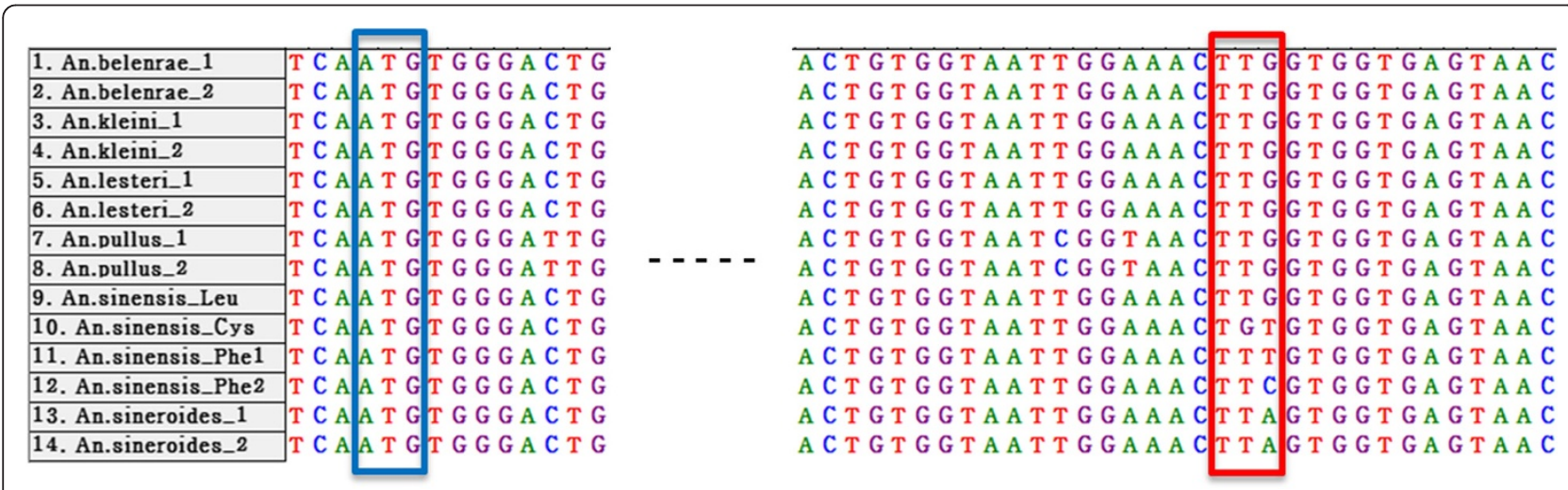

Figure 2 Alignment of multiple DNA sequences at codon 918 and codon 1014 within the voltage-gated sodium channel gene in the An. sinensis complex in the ROK. The blue box indicates codon 918 and the red box indicates codon 1014. 
monitoring insecticide susceptibilities and the resistance of target vectors in control programmes. Effective resistance monitoring that is based on species-specific insecticide bioassay tests, molecular studies of allele diversity, origins of insecticide resistance, and minor resistance mechanisms (behavioural and cuticular resistance) will be crucial for building successful malaria vector control programmes that can explain and predict the development and spread of insecticide resistance traits.

\section{Conclusions}

This is the first report that has explored the presence and absence of 1014 codon mutations in the VGSC of the six malaria-vector species in the ROK. The highly polymorphic 1014 mutations were only observed in $A n$. sinensis s.s., while the other five species showed no mutations. In An. sinensis s.s., the rarest allele, L1014F (TTC), was detected for the first time in this study, and the distribution of this allele was restricted to the southeast of the ROK. The present study is the first step in exploring species-specific insecticide resistance mechanisms. Further in-depth experiments are needed to prove the current epidemiological and evolutionary dynamics of malaria vectors in the ROK. In addition, these efforts will be one of the prerequisite steps needed to establish effective long-term vector control strategies in the ROK.

\section{Competing interests}

The authors declare that they have no competing interests.

\section{Acknowledgements}

We would like to thank Professor Han-II Ree (Department of Parasitology and Institute of Tropical Medicine, College of Medicine, Yonsei University) for field collections of mosquito specimens. This work was supported by the BK21 Research Fellowship from the Ministry of Education, Science and Technology, Republic of Korea.

\section{Author details}

${ }^{1}$ School of Biological Sciences, Seoul National University, 599 Gwanak-ro, Seoul, Republic of Korea. ${ }^{2}$ Department of Science Education, Ewha Womans University, 52 Ewhayeodae-gil, Seoul, Republic of Korea.

\section{Authors' contributions}

SK performed the molecular assays, data analysis, and manuscript writing. JJ collected field samples and identified the mosquitoes based on their morphological characteristics. SL and HH identified the mosquitoes by molecular identification methods. JJ and WK supervised the work and manuscript writing. WK was responsible for the management of and fund raising for this study. All authors read and approved the final manuscript.

Received: 03 December 2011 Accepted: 3 May 2012

Published: 3 May 2012

\section{References}

1. Chai IH, Lim Gl, Yoon SN, Oh WI, Kim SJ, Chai JY: Occurrence of tertian malaria in a male patient who has never been abroad. Korean $\mathrm{J}$ Parasitol 1994, 32:195-200.

2. Lee WJ, Klein TA, Kim HC, Choi YM, Yoon SH, Chang KS, Chong ST, Lee IY, Jones JW, Jacobs JS, Sattabongkot J, Park JS: Anopheles kleini, Anopheles pullus, and Anopheles sinensis: potential vectors of Plasmodium vivax in the Republic of Korea. J Med Entomol 2007, 44:1086-1090
3. Ree HI: Unstable vivax malaria in Korea. Korean J Parasitol 2000, 38:119-138.

4. Han ET, Lee DH, Park KD, Seok WS, Kim YS, Tsuboi T, Shin EH, Chai JY: Reemerging vivax malaria: changing patterns of annual incidence and control programs in the Republic of Korea. Korean J Parasitol 2006, 44:285-294.

5. Rueda LM: Two new species of Anopheles (Anopheles) Hyrcanus group (Diptera: Culicidae) from the Republic of South Korea. Zootaxa 2005, 941:1-26.

6. Tanaka K, Mizusawa K, Saugstad ES: A Revision of the adult and larval mosquitoes of Japan (including the Ryukyu Archipelago and the Ogasawara Islands) and Korea (Diptera: Culicidae). Contrib Am Entomol Inst 1979, 16:1-987.

7. Mosquito Taxonomic Inventory [http://mosquito-taxonomic-inventory.info/ sites/mosquito-taxonomic-inventory.info/files/Anopheles\% 20classification_24.pdf]

8. Hwang UW: Revisited ITS2 phylogeny of Anopheles (Anopheles) Hyrcanus Group mosquitoes: reexamination of unidentified and misidentified ITS2 sequences. Parasitol Res 2007, 101:885-894.

9. Li C, Lee JS, Groebner JL, Kim HC, Klein TA, O'guinn ML, Wilkerson RC: A newly recognized species in the Anopheles Hyrcanus Group and molecular identification of related species from the Republic of South Korea (Diptera: Culicidae). Zootaxa 2005, 939:1-8.

10. Lee DK, Lee YJ, Kim HC: Seasonal prevalence and host-seeking of mosquitoes in southeastern Republic of Korea. Entomol Res 2009, 39:257-265.

11. Ma Y, Qu F, Xu F, Li X, Song G: Differences in sequences of ribosomal DNA second internal transcribed spacer among three members of Anopheles hyrcanus complex from the Republic of Korea. Insect Sci 2000, 7:36-40.

12. Min GS, Choochote W, Jitpakdi A, Kim SJ, Kim W, Jung J, Junkum A: Intraspecific hybridization of Anopheles sinensis (Diptera: Culicidae) strains from Thailand and Korea. Mol Cells 2002, 14:198-204.

13. Ree HI: Studies on Anopheles sinensis, the vector species of vivax malaria in Korea. Korean J Parasitol 2005, 43:75-92.

14. Shin EH, Kim HK, Park C, Lee DK, Kang H, Chang KS: Insecticide susceptibility and resistance of Culex tritaeniorhynchus (Diptera: Culicidae) larvae collected from Gwangju, Republic of Korea. Entomol Res 2011, 41:157-160.

15. Joshi D, Choochote W, Park MH, Kim JY, Kim TS, Suwonkerd W, Min GS: The susceptibility of Anopheles lesteri to infection with Korean strain of Plasmodium vivax. Malar J 2009, 8:42.

16. Wilkerson RC, Li C, Rueda LM, Kim HC, Klein TA, Song GH, Strickman D: Molecular confirmation of Anopheles (Anopheles) lesteri from the Republic of South Korea and its genetic identity with An. (Ano.) anthropophagus from China (Diptera: Culicidae). Zootaxa 2003, 378:1-14.

17. Joshi D, Kim JY, Choochote W, Park MH, Min GS: Preliminary vivax malaria vector competence for three members of the Anopheles Hyrcanus group in the Republic of Korea. J Am Mosa Control Assoc 2011, 27:312-314.

18. Coleman RE, Kiattibut C, Sattabongkot J, Ryan J, Burkett DA, Kim HC, Lee WJ, Klein TA: Evaluation of anopheline mosquitoes (Diptera: Culicidae) from the Republic of Korea for Plasmodium vivax circumsporozoite protein. J Med Entomol 2002, 39:244-247.

19. Rueda LM, Li C, Kim HC, Klein TA, Foley DH, Wilkerson RC: Anopheles belenrae, a potential vector of Plasmodium vivax in the Republic of Korea. J Am Mosa Control Assoc 2010, 26:430-432.

20. Davidson G: The five mating-types in the Anopheles gambiae complex. Riv Malariol 1964, 43:167.

21. Slotman M, Torre AD, Powell JR: Female sterility in hybrids between Anopheles gambiae and A. arabiensis, and the causes of Haldane's rule. Evolution 2005, 59:1016-1026.

22. Temu EA, Hunt RH, Coetzee M, Minjas JS, Shiff CJ: Detection of hybrids in natural populations of the Anopheles gambiae complex by the rDNAbased, PCR method. Ann Trop Med Parasitol 1997, 91:963.

23. White GB: Chromosomal evidence for natural interspecific hybridization by mosquitoes of the Anopheles gambiae complex. Nature 1971, 231:184-185.

24. Djogbénou L, Chandre F, Berthomieu A, Dabiré R, Koffi A, Alout H, Weill M: Evidence of Introgression of the ace-1R mutation and of the ace-1 duplication in West African Anopheles gambiae s. s. PLoS One 2008, 3:e2172.

25. Garcia BA, Caccone A, Mathiopoulos KD, Powell JR: Inversion monophyly in African anopheline malaria vectors. Genetics 1996, 143:1313.

26. Weill M, Chandre F, Brengues C, Manguin S, Akogbeto M, Pasteur N, Guillet $\mathrm{P}$, Raymond M: The kdr mutation occurs in the Mopti form of Anopheles gambiae s.s. through introgression. Insect Mol Biol 2000, 9:451-455. 
27. Joshi D, Choochote W, Min GS: Natural hybrid between Anopheles kleini and Anopheles sinensis. Am J Trop Med Hyg 2009, 81:1020-1022.

28. Rivero A, Vézilier J, Weill M, Read AF, Gandon S: Insecticide control of vector-borne diseases: when is insecticide resistance a problem? PLOS Pathol 2010, 6:e1001000.

29. Hemingway J, Hawkes NJ, McCarroll L, Ranson H: The molecular basis of insecticide resistance in mosquitoes. Insect Biochem Mol Biol 2004, 34:653-665.

30. Diabate A, Brengues C, Baldet T, Dabiré KR, Hougard JM, Akogbeto M, Kengne P, Simard F, Guillet P, Hemingway J, Chandre F: The spread of the Leu-Phe $k d r$ mutation through Anopheles gambiae complex in Burkina Faso: genetic introgression and de novo phenomena. Trop Med Int Health 2004, 9:1267-1273

31. Enayati AA, Vatandoost $\mathrm{H}$, Ladonni $\mathrm{H}$, Townson $\mathrm{H}$, Hemingway J: Molecula evidence for a $k d r$ like pyrethroid resistance mechanism in the malaria vector mosquito Anopheles stephensi. Med Vet Entomol 2003, 17:138-144.

32. Hoti SL, Vasuki V, Jambulingam P, Sahu SS: kdr allele-based PCR assay for detection of resistance to DDT in Anopheles culicifacies sensu lato Giles population from Malkangiri District, Orissa, India. Curr Sci 2006, 91:658-661.

33. Karunaratne S, Hawkes NJ, Perera MDB, Ranson H, Hemingway J: Mutated sodium channel genes and elevated monooxygenases are found in pyrethroid resistant populations of Sri Lankan malaria vectors. Pestic Biochem Physiol 2007, 88:108-113.

34. Kim H, Baek JH, Lee WJ, Lee SH: Frequency detection of pyrethroid resistance allele in Anopheles sinensis populations by real-time PCR amplification of specific allele (rtPASA). Pestic Biochem Physiol 2007, 87:54-61.

35. Luleyap HU, Alptekin D, Kasap H, Kasap M: Detection of knockdown resistance mutations in Anopheles sacharovi (Diptera: Culicidae) and genetic distance with Anopheles gambiae (Diptera: Culicidae) using cDNA sequencing of the voltage-gated sodium channel gene. J Med Entomol 2002, 39:870-874.

36. Martinez Torres D, Chandre F, Williamson MS, Darriet F, Berge JB, Devonshire AL, Guillet P, Pasteur N, Pauron D: Molecular characterization of pyrethroid knockdown resistance $(k d r)$ in the major malaria vector Anopheles gambiae s.s. Insect Mol Biol 1998, 7:179-184.

37. Syafruddin D, Hidayati A, Asih P, Hawley W, Sukowati S, Lobo N: Detection of $1014 \mathrm{~F} k d r$ mutation in four major anopheline malaria vectors in Indonesia. Malar J 2010, 9:315.

38. Donnelly MJ, Corbel V, Weetman D, Wilding CS, Williamson MS, Black Iv WC: Does $k d r$ genotype predict insecticide-resistance phenotype in mosquitoes? Trends Parasitol 2009, 25:213-219.

39. Tan WL, Wang ZM, Li CX, Chu HL, Xu Y, Dong YD, Wang Z, Chen DY, Liu H, Liu DP: First report on co-occurrence knockdown resistance mutations and susceptibility to beta-cypermethrin in Anopheles sinensis from Jiangsu Province. China. PLoS One 2012, 7:e29242.

40. Chang KS, Jung JS, Park C, Lee DK, Shin E: Insecticide susceptibility and resistance of larvae of the Anopheles sinensis goup (Diptera: Culicidae) from Paju, Republic of Korea. Entomol Res 2009, 39:196-200.

41. Ree HI, Paik YH: Insecticide susceptibility tests on adults of Anopheles sinensis in Korea. Korean J Parasitol 1967, 5:65-68.

42. Shin E, Park YI, Lee HI, Lee WJ, Shin YH, Shim JC: Insecticide susceptibilities of Anopheles sinensis (Diptera: Culicidae) larvae from Paju-shi, Korea. Entomol Res 2003, 33:33-37.

43. Awolola TS, Brooke BD, Koekemoer $\mathrm{LL}$, Coetzee M: Absence of the $k d r$ mutation in the molecular ' $\mathrm{M}$ ' form suggests different pyrethroid resistance mechanisms in the malaria vector mosquito Anopheles gambiae s.s. Trop Med Int Health 2003, 8:420-422.

44. Chen B, Pedro PM, Harbach RE, Somboon P, Walton C, Butlin RK: Mitochondrial DNA variation in the malaria vector Anopheles minimus across China, Thailand and Vietnam: evolutionary hypothesis, population structure and population history. Heredity 2010, 106:241-252.

45. Cui F, Raymond M, Qiao CL: Insecticide resistance in vector mosquitoes in China. Pest Manage Sci 2006, 62:1013-1022.

46. Verhaeghen K, Van Bortel W, Trung HD, Sochantha T, Keokenchanh K, Coosemans M: Knockdown resistance in Anopheles vagus, An. sinensis, An. paraliae and An. peditaeniatus populations of the Mekong region. Parasit Vectors 2010, 3:59.

47. Joshi D, Park MH, Saeung A, Choochote W, Min GS: Multiplex assay to identify Korean vectors of malaria. Mol Ecol Resour 2010, 10:748-750.

48. Larkin MA, Blackshields G, Brown NP, Chenna R, McGettigan PA, McWilliam H, Valentin F, Wallace IM, Wilm A, Lopez R: Clustal W and Clustal X version 2.0. Bioinformatics 2007, 23:2947.
49. Kumar S, Tamura K, Nei M: MEGA3: integrated software for molecular evolutionary genetics analysis and sequence alignment. Brief Bioinform 2004, 5:150-163

50. Post RJ, Millest AL: Sample size in parasitological and vector surveys. Parasitol Today 1991, 7:141.

51. Davies TGE, Field LM, Usherwood PNR, Williamson MS: A comparative study of voltage-gated sodium channels in the Insecta: implications for pyrethroid resistance in Anopheline and other Neopteran species. Insect Mol Biol 2007, 16:361-375.

52. Soderlund DM: Pyrethroids, knockdown resistance and sodium channels. Pest Manage Sci 2008, 64:610-616.

53. Shim JC, Shin EH, Yang DS, Lee WK: Seasonal prevalence and feeding time of mosquitoes (Diptera: Culicidae) at outbreak regions of domestic malaria (P. vivax) in Korea. Korean J Entomol 1997, 27:265-278.

54. Chai JY: Re-emerging malaria. J Korean Med Assoc 1997, 40:728-733.

55. Chai JY: Re-emerging Plasmodium vivax malaria in the Republic of Korea. Korean J Parasitol 1999, 37:129.

56. Kho WG, Jang JY, Hong ST, Lee HW, Lee WJ, Lee JS: Border malaria characters of reemerging vivax malaria in the Republic of Korea. Korean $\lrcorner$ Parasitol 1999, 37:71.

57. Ree HI: Can malaria be endemic in South Korea? Korean J Infect Dis 1998, 30:397-400.

58. Crow JF, Kimura M: An introduction to population genetics theory. New York: Harper \& Row; 1970

59. Frankham R: Relationship of genetic variation to population size in wildlife. Conserv Biol 1996, 10:1500-1508.

60. Soulé M: Allozyme variation: its determinants in space and time. In Molecular Evolution. Edited by Ayala F, Sunderland MA. Sunderland, MA: Sinauer Associates; 1976:60-77.

61. Fowlie $M$, Krüger $\mathrm{O}$ : The evolution of plumage polymorphism in birds of prey and owls: the apostatic selection hypothesis revisited. J Evol Biol 2003, 16:577-583.

62. Jung J, Jung $Y$, Min GS, Kim W: Analysis of the population genetic structure of the malaria vector Anopheles sinensis in South Korea based on mitochondrial sequences. Am J Trop Med Hyg 2007, 77:310.

doi:10.1186/1475-2875-11-151

Cite this article as: Kang et al:: The polymorphism and the geographical distribution of the knockdown resistance $(k d r)$ of Anopheles sinensis in the Republic of Korea. Malaria Journal 2012 11:151.

\section{Submit your next manuscript to BioMed Central and take full advantage of:}

- Convenient online submission

- Thorough peer review

- No space constraints or color figure charges

- Immediate publication on acceptance

- Inclusion in PubMed, CAS, Scopus and Google Scholar

- Research which is freely available for redistribution 